\title{
Health Risk \& Precautions for People Living with HIV/AIDS (PLHIV) in Global Pandemic COVID-19
}

\author{
Mr. Stephen John ${ }^{1 *}$, Dr. Praveen S Pateel ${ }^{2}$ \\ ${ }^{1}$ Asso.Professor, GIMS Govt. College of Nursing, Mallasamudra, Gadag \\ ${ }^{2}$ Asso.Professor, BVVS Sajjalashree Institute of Nursing Sciences, Bagalkot
}

DOI: $\underline{10.36348 / \mathrm{sjnhc} .2021 . v 04 \mathrm{i} 03.008}$

| Received: 19.02.2021 | Accepted: 20.03.2021 | Published: 30.03.2021

*Corresponding author: Mr. Stephen John

\section{Abstract}

Human Immunodeficiency Virus / Acquired Immune Deficiency Syndrome (HIV/AIDS) is a chronic, life taking and helpless condition that arouses due to compromised functioning of a person's immune system. According to National Health Policy-2015 growth of HIV/AIDS should have been controlled by the year 2007 but we have failed drastically in achieving it. Corona Virus Disease (COVID-19) has added to the burden of it. In an attempt to prevent and control COVID-19 the whole of globe stopped functioning and even the health care services related to people living with HIV/AIDS came to a stalemate. Its an attempt through this article to summarise the risk and precaution to be taken by people living with HIV/AIDS during pandemic.

Keywords: HIV/AIDS, PLHIV, Health, Pandemic, COVID-19.

Copyright (C) 2021 The Author(s): This is an open-access article distributed under the terms of the Creative Commons Attribution 4.0 International License (CC BY-NC 4.0) which permits unrestricted use, distribution, and reproduction in any medium for non-commercial use provided the original author and source are credited.

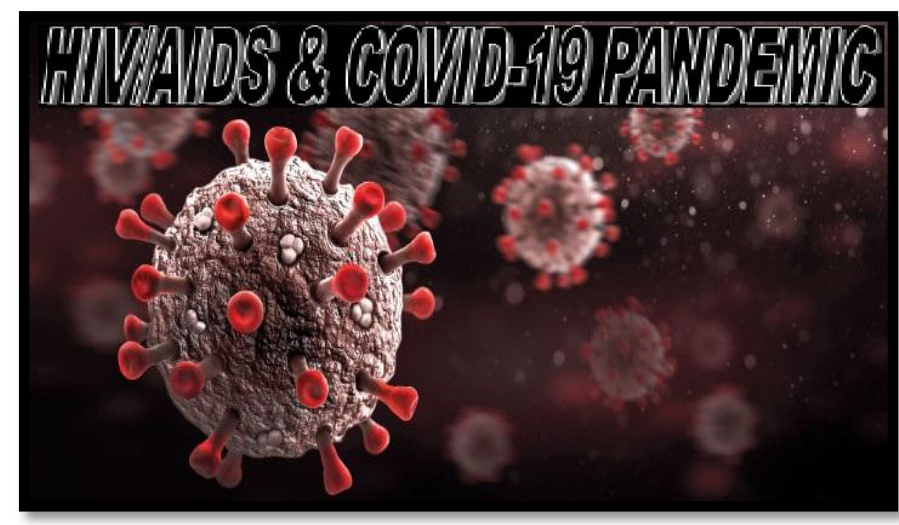

\section{INTRODUCTION}

HIV/AIDS originated in non human primates in central and West Africa. The global pandemic of HIV/AIDS in 1980s was due to the primary strain (i.e.) HIV-1. It was a global health disaster of $19^{\text {th }}$ century accounting for death toll of 32 million plus till date [1].

Corona virus pandemic is an ongoing pandemic of corona virus disease 2019 (COVID-19). COVID-19 originated in December 2019 at Wuhan, China. The Etiology of the disease is Severe Acute Respiratory Syndrome Corona Virus 2 (SARS-CoV-2). In January 2020 it was declared as public health emergency and as a global pandemic in march 2020 accounting for death toll of 1.09 million as on $14^{\text {th }}$ oct.2020 [2].

Health care crisis occured by covid 19 global pandemic among plhiv

Currently, our world is suffering with the wrath of COVID-19 and has made living bitter and harder for common people, but for people belonging to special groups like people living with HIV/AIDS; it has left with no choice than to compromise on essential health care services and their health status as a whole.

According to a rapid assessment conducted by The European AIDS Treatment Group (EATG) a Non- 
Stephen John \& Praveen S Pateel., Saudi J Nurs Health Care, Mar, 2021; 4(3): 88-90

Governmental Organization that protects and cares HIV affected people, relates to the crisis occurred by COVID-19 in the following areas.

- Essential institutional health care service including medical consultation, Nursing care services, drug dispensing were disrupted.

- HIV sampling, testing (diagnostic services) and preventive care services.

- Community health care services like survey, health checkups of PLHIV at their homes.

- Shortage of essential Medicine supply. [AntiRetroviral Therapy(ART) Drugs][3]

\section{Impact of covid 19 on plhiv}

The impact of COVID-19 on people living with HIV/AIDS is invariably in every dimensions of life. The major dimensions are based on dimensions of health by world health organization (i.e.) physical, mental, social, spiritual and economical dimensions.

\section{Physical dimension}

It relates to the physical health of people living with HIV/AIDS. All the factors contributing to physical health are compromised due to the rise in COVID-19 cases. Few activities like lack of exercise, inadequate nutrition, no travelling, lack of medications, and shortage of vegetables/groceries and breathing difficulties due to masking over period of time have diversely affected the health of PLHIV.

\section{Mental dimension}

It signifies the mental capacity of people living with HIV/AIDS to successfully deal with the problems. According to a study conducted on challenges to HIV care in COVID-19 Pandemic [4], the following mental issues were found.

- Depression was at higher note, $60.8 \%$ of samples reported it.

- Stress due to unwanted exposure of one's HIV status while ART drug mailing.

- To avoid Social stigma and discrimination People Living with HIV/AIDS chose to discontinue their medicine during quarantine to conceal their HIV status from parents, neighbours \& relatives.

- $\quad 49.8 \%$ of samples reported anxiety and $38.5 \%$ of samples reported insomnia respectively.

\section{Social dimension}

In society, just attempting to know HIV status in itself is so suspicious and gives rise to rumours on an individual's dignity and active sexual relationship, in such sensitive situation, handling people affected with HIV/AIDS is a challenge and this challenge is aggravated by COVID-19 (covidization).

The narration by a client during a qualitative study brought to light a few ill social effects of COVID19, measures like lock down, social distancing and prohibition of social gathering/functions to control and contain COVID-19 had adverse effect on common people and also on people living with HIV/AIDS. Following were the themes from the clients narration [5].

- Sense of isolation

- Social ostracism

- Perceived sense of neglect by health staff due to fear of acquiring it.

- Intensification of distress : primary disease plus covid-19

\section{Spiritual dimension}

Spirituality is a neglected or less important dimension among all the dimensions of health to an individual. A supreme power (God) is mostly remembered in times of trouble and help. In case of people living with HIV/AIDS He/She (God) is the only hope.

Due to COVID-19 all religious institutions like Churches, Temples \& mosque were closed. Seeking spiritual support was a challenge. Most commonly all help provided was online/ telephonically.

\section{Economical dimension}

The health care expenditure and financial stress go very closely with each other. All the ART drugs and diagnostics are made free by the government at ART center but the financial crisis due to job loss secondary to disease condition, no employment due to COVID-19 health emergency adds to the financial burden and this is aggravated if the affected person is sole bread winner of the family.

The financial help rendered by government agencies and other agencies are very bleak to meet the need of the individual and family as a whole. The present burden to Indian families affected with HIV/AIDS is spending out of pocket for health care services (if no health insurance is enrolled) due to COVID-19 as there is no employment and no source of income, ultimately, leading to financial toxicity.

\section{FAST FACT ON COVID -19 AND PLHIV/AIDS}

Based on an article by avert organisation, following are the fast facts on COVID-19 and PLHIV/AIDS [6].

- PLHIV/AIDS who are on effective AntiRetroviral Therapy have minimal risk with COVID-19.

- PLHIV/AIDS who are not on Anti-Retroviral Therapy are at risk to acquire COVID-19.as like no concrete evidence is still made available.

- PLHIV/AIDS who have co-mobidities and old age factor are at minimal risk to acquire COVID-19. 
Stephen John \& Praveen S Pateel., Saudi J Nurs Health Care, Mar, 2021; 4(3): 88-90

- $\quad$ PLHIV/AIDS with high viral load, low $\mathrm{CD}_{4}$ cell count and opportunistic infection are at high risk to COVID-19.

\section{Stratergies/techniques for people living with hiv/aids to maintain health in fight against covid-19 [7, 8] \\ - Wash hands regularly with soap and water. \\ - Effective use of mask and sanitizer. \\ - Avoid touching face, nose and eyes to prevent cross infection.}

- Follow the principles of social distancing and walk out of house only when needed.

- Spend time with family in-house in prayers and other recreational activities.

- Keep yourself physically active by doing active and passive exercises for musculoskeletal health.

- Look after your mental health by avoiding unwanted newsfeeds and social media.

- Ensure healthy eating habits with high calorie, high protein diet and avoid alcohol /tobacco.

- Stay hydrated, drink enough water and juice to keep you hydrated.

- Balance the financial expenditures and avoid any expenses that can be postponed.

- $\quad$ Stock up ART medications atleast of 01 month before hand. Conveniently, for 03 months.

- If possible, undergo needed diagnostic health care services to keep an eye on viral load and $\mathrm{CD}_{4}$ cell count and act judiciously.

- In worst case, plan to gain health care services from the designated COVID CARE CENTER.

\section{CONCLUSION}

A systematic review was conducted on COVID-19 outcomes in HIV/AIDS patient. Using Preferred Reporting Items for Systematic Reviews and Meta-analysis - PRISMA guidelines a total of 285 articles were identified and after preliminary screening 08 studies were analysed which concluded that further in-depth enquiry is needed for concrete conclusion about whether people living with HIV/AIDS are at more risk than the general population for COVID-19 infection [9].

The intent of this article is to summarise in the simplest way, the risk related to COVID-19 in people living with HIV/AIDS and precaution to be taken by people living with HIV/AIDS to counterfeit the risks to stay healthy and lead a quality life. The conclusion of this article is based on a systematic review conducted between December 2019 to June 2020 suggests that identifying of co-infections, effective management of co-morbidities and ensuring a secure supply of Anti-
Retroviral Therapy drugs during COVID-19 global pandemic can be the essentialities of people living with HIV/AIDS in endurance to a safe and healthy life [10].

\section{REFERENCES}

1. Wikipedia.org. (2020). History of HIV/AIDS online resources, [updated 2020 oct 14 ; cited 2020 oct 14]available from: https://en.wikipedia.org/wiki/History_of_HIV/AID $\mathrm{S}$

2. Wikipedia.org.covid-19 online resources, [updated 2020 oct 14 ;cited 2020 oct 14]available from: https://en.wikipedia.org/wiki/COVID-19_pandemic

3. Dpnsee.org. (2020). European AIDS Treatment Group, COVID-19 crisis' impact on PLHIV. [updated 2020 oct 14 ;cited 2020 oct 14] available from: http://dpnsee.org/2020/04/12/covid-19-crisisimpact-on-plhiv-and-on-communities-mostaffected-by-hiv/

4. Sun, S., Hou, J., Chen, Y., Lu, Y., Brown, L., \& Operario, D. (2020). Challenges to HIV care and psychological health during the COVID-19 pandemic among people living with HIV in China. AIDS and Behavior, 24, 2764-2765.

5. Bhattacharya, S. (2020). The Social Impact of the COVID-19 Pandemic. [cited 2020 oct 17] available from : https://www.orfonline.org/research/thesocial-impact-of-the-covid19-pandemic/

6. Avert.org. (2020). AVERT, Global information and education on HIV\& AIDS. COVID-19 and HIV. [updated 2020 oct 14 ;cited 2020 oct 19] available from: httpswww.avert.orgcoronaviruscovid19-HIV

7. Who.int. (2020). World Health Organisation. \#Healthy at Home [updated 2020 oct 14;cited 2020 oct 19] available from: https://www.who.int/campaigns/connecting-theworld-to-combatcoronavirus /healthyathome? gclid $=$ CjwKCAjwz6_8BRBkEiw A3p 02V c2hHpoUQQU17h-

EyuWemW7ybd0aTA2iEouLoehdvtM2s0PJAZku ohoCrV4QAv D_BwE

8. Who.int. (2020). World Health Organisation. HIV/AIDS: A Guide For Nutrition, Care and Support. [updated 2020 oct 14 ; cited 2020 oct 19] https://www.who.int/hac/techguidance/pht/8518.pd $\mathrm{f}$

9. Cooper, T. J., Woodward, B. L., Alom, S., \& Harky, A. (2020). Coronavirus disease 2019 (COVID- 19) outcomes in HIV/AIDS patients: a systematic review. HIV medicine, 21(9), 567-577.

10. Mirzaei, H., McFarland, W., Karamouzian, M., \& Sharifi, H. (2020). COVID-19 among people living with HIV: a systematic review. AIDS and Behavior, 1-8. 